\title{
Chemical characteristics and nutritive values of super-genotype of oat vs normal varieties of oats for ruminants*
}

\author{
Z. Niu' ${ }^{1}$, B.G. Rossnagel ${ }^{2}$ and P. Yu ${ }^{2,3}$ \\ University of Saskatchewan, \\ ${ }^{1}$ Department of Animal and Poultry Science, \\ ${ }^{2}$ Crop Development Centre \\ Saskatoon, Saskatchewan S7N 5A8, Canada
}

\begin{abstract}
The objectives of this study were to determine the magnitude of differences among oat varieties (new super-genotype vs normal) of in terms of detailed chemical composition and in situ degradation kinetics of nutrient components for ruminants. Six oat samples comprised of 3 cultivars (CDC Dancer, Derby and CDC SO-I) grown over two years $(2005,2006)$ were obtained from the Crop Development Centre. The results show different chemical and nutritive characteristics among oat varieties. The in situ trial revealed that nutrient disappearance of $\mathrm{DM}, \mathrm{CP}$ and starch followed the same trend. Further study is on modeling nutrient supply (protein and energy).
\end{abstract}

KEY WORDS: super-genotype, oat, degradation, nutrient, ruminants

\section{INTRODUCTION}

Oat is of the genus Avena, family Gramineae, and thrives in moist, temperate regions of the world, though they may be cultivated in a variety of climates (Heiser, 1973). The most widely cultivated species is the Avena sativa, a cereal grass used for food and fodder. In situ degradability of DM, CP and starch of oat was studied by HerreraSaldana et al. (1990). They observed that oat had highly degradable DM, CP and starch, about $80 \%$ DM and greater that $90 \%$ of total CP and starch in oat disappeared during first $2 \mathrm{~h}$ of rumen incubation. Recent developments by The Crop Development Centre (Canada) have showed promise for oat use in dairy rations. This type of oat contains low-lignin hull (LLH) and high-fat groat (HOG), and is low in acid detergent

\footnotetext{
${ }^{*}$ Supported by Saskatchewan Agricultural Development Fund

${ }^{3}$ Corresponding author: e-mail: pey582@mail.usask.ca
} 
lignin (ADL) and has greater ruminal degradability, thus, LLH-HOG oat should be a superior oat for feeding dairy cattle (Fuhr, 2006). The objectives of this study were to determine the magnitude of differences among the 3 cultivars (super-genotype: CDC SO-I vs normal: CDC Dancer, Derby) in terms of chemical composition and in situ degradation kinetics of components, and provide detailed feeding values for ruminants. It was hypothesized that LLH-HOG oat (CDC SO-I) have superior nutritional characteristics for dairy cows when compared to conventional oat.

\section{MATERIAL AND METHODS}

\section{Oats samples}

Six oat samples, the cultivars CDC Dancer, Derby and CDC SO-I grown over two years (2005 and 2006) were provided by the Crop Development Centre. The samples were ground through $0.5 \mathrm{~mm}$ and $1 \mathrm{~mm}$ pore size screens for chemical analysis. The samples ground through $0.5 \mathrm{~mm}$ were for starch, and $1 \mathrm{~mm}$ for other chemical analyses. For rumen in situ work, the oats were processed through $0.533 \mathrm{~mm}$ gap roller mill at the engineer lab.

\section{Animals and diets}

Three Holstein dry cows fitted with rumen cannula with an internal diameter of 10 $\mathrm{cm}$ were used for determination of rumen degradation of nutrients. The cows were housed at a tie stall at the experimental station at the University of Saskatchewan (Canada). The cows were fed twice daily at 8.00 and 16.00 by receiving $14 \mathrm{~kg} \mathrm{DM}$ (7 kg at each feeding time) of total mixed ration (TMR), consisting of, \%: barley silage 56.82 , lucerne hay 10.23 , dehydrated lucerne pellets 4.54 , standard dairy concentrate 21.59 and fresh cow concentrate 6.82 . Water was always available. The cows were allowed for free access to the exercise grounds inside and outside. The animals used in the experiment were cared for in accordance with the guidelines of the CCAC (1993).

\section{In situ rumen incubation}

Rumen degradation of nutrients for all oat samples was evaluated using the in situ technique (Yu et al., 2003). Incubation of all treatments in the rumen was conducted with number-coded nylon bags with pore size $43 \mu \mathrm{m}$. Incubations were performed according to the gradual addition/all out schedule. Residues from the same Run were pooled according to treatment, and subsequently ground through $1 \mathrm{~mm}$ screen for analysis of DM, CP, and $0.5 \mathrm{~mm}$ screen for analysis of starch using Retsch grinder. 


\section{Chemical analysis}

The DM, EE, ash and CP were determined according to procedures of AOAC (1990). Starch was analysed by enzymatic hydrolysis and spectrometry using the Megazyme total starch kit according to McCleary et al. (1997). NDF and ADF were determined using Ankom Fiber Analyzer (Ankom Technology Corporation, Fairport, NY) by incubating samples in neutral detergent solution (Van Soest et al., 1991) and acid detergent solution (AOAC, 1990). ADL was determined by washing ADF residue with $20 \mathrm{~N} \mathrm{H}_{2} \mathrm{SO}_{4}$ (AOAC, 1990). Buffer SCP was determined according to Roe et al. (1990). NPN was determined by the methods of Licitra et al. (1996). Total nitrogen of NDF and ADF residues were analysed for NDICP and ADICP respectively (Licitra et al., 1996). The difference between buffer insoluble crude protein and NDICP was used to estimate the true protein (TP). The $\mathrm{CHO}$ and $\mathrm{TP}$ were calculated according to formula of the NRC - Dairy (2001) and NRC - Beef (1996).

\section{Statistical analysis}

Statistical analyses were performed using Proc mixed model procedure of SAS (2005). The treatment means were separated using Fisher's LSD test (Steel and Torrie, 1980) with significance set at $\mathrm{P}<0.05$.

\section{RESULTS AND DISCUSSION}

CDC SO-I oat had similar chemical composition in DM, NDF, ADF, starch, CP, NPN, SCP, ADICP and NDICP to CDC Dancer and Derby. However, it was higher in ash, EE and cellulose, and lower in CHO, OM, ADL and NFC (Table 1). The results indicated that $\mathrm{CDC}$ SO-I had more digestible fibre than conventional oat due to its lower lignin and non fibre carbohydrate. Most of the chemical composition data, especially that for Derby, was close to values in NRC Dairy (2001) and NRC Beef (1996). However, lignin contents were 3.91, 3.60 and 2.12\% for CDC Dancer, Derby and CDC SO-I, respectively, while the NRC Dairy (2001) value is $4.9 \%$, while Fuhr (2006) reported that the lignin content of Derby and LLH-HOG at 2.6 and $1.1 \%$ of DM, respectively. Our lignin results were intermediate to those values. The NDF, ANF and ADICP values are similar to those of the NRC Dairy (2001) and Herrera-Saldana et al. (1990) who reported that NDF, ADF and ADICP of oat were $24.0,16.5$ and $0.3 \%$ of DM, respectively. NRC-Dairy (2001) values were $30.0,14.6$ and $0.3 \%$ of DM for NDF, ANF and ADICP, respectively. Although NDF content of CDC SO-I was about 5.3 and 3.2\% higher than that of CDC Dancer and Derby, the difference was not statistically significant, and it was considerably lower than $38.0 \%$ reported by Fuhr (2006) using a different LLH-HOG prototype sample. 
These results suggest that hull content of CDC SO-I is greater than that of Derby, in particular CDC Dancer. A future breeding goal is to reduce the hull percentage and then NDF content of LLH-HOG oat to levels similar to CDC Dancer.

Table 1. Chemical composition of different cultivar of oats (Avena sativa)

\begin{tabular}{|c|c|c|c|c|c|c|}
\hline \multirow{2}{*}{ Items } & \multicolumn{3}{|c|}{ Oats } & \multirow{2}{*}{ SEM } & \multicolumn{2}{|c|}{$P$ value } \\
\hline & CDC Dancer & Derby & CDC SO-I & & oat & year \\
\hline$\overline{\mathrm{DM}}, \%$ & 93.88 & 93.88 & 94.08 & 0.185 & 0.711 & 0.848 \\
\hline Ash, \%DM & $3.17^{\mathrm{b}}$ & $3.15^{\mathrm{b}}$ & $3.59^{\mathrm{a}}$ & 0.053 & 0.045 & 0.075 \\
\hline $\mathrm{EE}, \% \mathrm{DM}$ & $4.57^{\mathrm{b}}$ & $4.01^{\mathrm{b}}$ & $5.85^{\mathrm{a}}$ & 0.153 & 0.026 & 0.267 \\
\hline $\mathrm{FA}, \% \mathrm{DM}$ & $3.57^{\mathrm{b}}$ & $3.01^{\mathrm{b}}$ & $4.85^{\mathrm{a}}$ & 0.153 & 0.026 & 0.267 \\
\hline $\mathrm{CHO}, \% \mathrm{DM}$ & $80.45^{\mathrm{a}}$ & $81.75^{\mathrm{a}}$ & $77.77^{\mathrm{b}}$ & 0.420 & 0.041 & 0.203 \\
\hline NDF, \%DM & 26.55 & 28.61 & 31.85 & 1.125 & 0.151 & 0.728 \\
\hline $\mathrm{ADF}, \% \mathrm{DM}$ & 11.83 & 13.93 & 13.92 & 0.520 & 0.155 & 0.789 \\
\hline $\mathrm{ADL}, \% \mathrm{DM}$ & $3.91^{\mathrm{a}}$ & $3.60^{\mathrm{a}}$ & $2.12^{\mathrm{b}}$ & 0.185 & 0.036 & 0.597 \\
\hline Hemicellulose, \%DM & 14.68 & 14.72 & 17.92 & 0.819 & 0.163 & 0.535 \\
\hline Cellulose, \%DM & $7.92^{\mathrm{b}}$ & $10.34^{\mathrm{a}}$ & $11.81^{\mathrm{a}}$ & 0.376 & 0.035 & 0.919 \\
\hline $\mathrm{ADL}, \% \mathrm{NDF}$ & $14.75^{\mathrm{a}}$ & $12.55^{\mathrm{b}}$ & $6.45^{\mathrm{c}}$ & 0.231 & 0.003 & 0.114 \\
\hline $\mathrm{ADF}, \% \mathrm{NDF}$ & 44.65 & 48.65 & 43.72 & 1.338 & 0.206 & 0.434 \\
\hline Starch, \%DM & 45.76 & 40.31 & 42.57 & 2.050 & 0.359 & 0.583 \\
\hline NFC, \%DM & $55.13^{\mathrm{a}}$ & $53.9^{\mathrm{a}}$ & $46.76^{b}$ & 0.608 & 0.018 & 0.223 \\
\hline NFC, \%CHO & 68.53 & 65.95 & 60.13 & 1.001 & 0.051 & 0.559 \\
\hline Starch, \%NFC & 83.09 & 74.78 & 91.09 & 4.702 & 0.250 & 0.430 \\
\hline $\mathrm{CP}, \% \mathrm{DM}$ & 11.82 & 11.10 & 12.81 & 0.294 & 0.106 & 0.342 \\
\hline NPN, \%CP & 13.43 & 9.88 & 15.62 & 1.569 & 0.227 & 0.118 \\
\hline NPN, \%DM & 1.59 & 1.09 & 2.01 & 0.239 & 0.214 & 0.189 \\
\hline NPN, \%SCP & 30.89 & 21.61 & 29.38 & 3.674 & 0.352 & 0.181 \\
\hline $\mathrm{SCP}, \% \mathrm{CP}$ & 43.43 & 46.05 & 53.13 & 2.394 & 0.186 & 0.674 \\
\hline SCP, \%DM & 5.13 & 5.12 & 6.8 & 0.362 & 0.123 & 0.972 \\
\hline ADICP, $\% \mathrm{CP}$ & 5.07 & 4.57 & 4.18 & 1.636 & 0.932 & 0.941 \\
\hline ADICP, \%DM & 0.60 & 0.51 & 0.54 & 0.196 & 0.942 & 0.896 \\
\hline NDICP, \%CP & 10.41 & 6.95 & 6.50 & 1.885 & 0.437 & 0.603 \\
\hline NDICP, \%DM & 1.23 & 0.77 & 0.83 & 0.216 & 0.423 & 0.513 \\
\hline
\end{tabular}

SEM - standard error of mean. Means with the different letters in the same row are significantly different $(\mathrm{P}<0.05)$

In situ DM, CP and starch disappearance are illustrated in Figure 1. DM, CP and starch of oats showed similar trends in terms of in situ disappearance. During the first $2 \mathrm{~h}$, DM disappearance were, \%: CDC Dancer 57.9, Derby 46.7 and for CDC SO-I 49.6; CP disappearance was, \%: CDC Dancer 67.89, Derby 56.84 and for CDC SO-I 63.80; starch disappearance was, \%: 7CDC Dancer 8.67, Derby 68.17 and for CDC SO-I 73.50. These characteristics of nutrient disappearance are similar to those reported by Herrera-Saldana et al. (1990). They observed 
that oat had highly degradable fraction of DM, CP and starch, about $80 \% \mathrm{DM}$ and greater than $90 \%$ of total $\mathrm{CP}$ and starch in oat disappeared during the first $2 \mathrm{~h}$ of rumen incubation. It is indicated that oat contained a highly degradable fraction which disappeared before $2 \mathrm{~h}$; thereafter, DM was degraded more slowly reflecting slow degradation of fibre from oat (11.8-13.9\% ADF). For CP disappearance, it is possible that globulins are highly degradable and constitute about $80 \%$ of total protein; while the starch is floury type made up of simple and complex granules which are rapidly degraded in the rumen (Herrera-Saldana et al., 1990).
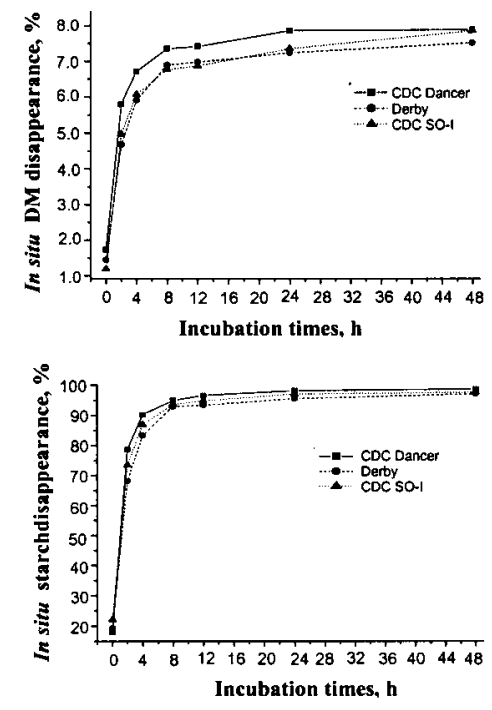

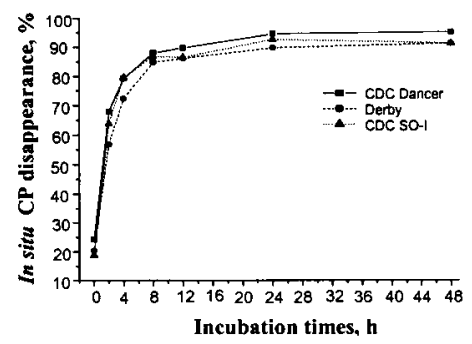

Incubation times, $h$

Figure 1. In situ rumen disappearance of dry matter (top left), crude protein (top right) and starch (bottom) of CDC Dancer, Derby and CDC SO-I

\section{CONCLUSIONS}

Chemical analysis revealed that CDC SO-I oat had more digestible fibre than conventional oat due to lower acid detergent lignin and non structural carbohydrate. The in situ trial revealed that nutrient disappearance of DM, CP and starch followed the same trend. Information obtained may help understand relative protein and starch degradability of oats in the rumen. It may also allow for combinations of energy and protein supplements for improved efficiency of nutrient utilization and improvement in animal performance. To better understand ruminant feeding characteristics of CDC SO-I, further study is needed re modeling nutrient supply, rumen degradation characteristics, microbial protein synthesis in the rumen, intestinal digestion of oatcontaining feed and microbial protein and degraded protein balance. 


\section{REFERENCES}

AOAC, 1990. Association of Official Analytical Chemists, Official Methods for Analysis. $15^{\text {th }}$ Edition. Washington, DC

Canadian Council on Animal Care, 1993. Guide to the Care and Use of Experimental Animals. Vol. 1. 2nd Edition. CCAC, Ottawa, ON

Fuhr L.G., 2006. Low lignin hull, high oil groat oat grain in lactating dairy cow ration. Master Thesis, University of Saskatchewan (Canada)

Heiser Jr. C.B., 1973. Seed to Civilization: The Story of Man's Food. San Francisco, W.H. Freeman

Herrera-Saldana R.E., Huber J.T., Poore M.H., 1990. Dry matter, crude protein, and starch degradability of five cereal grains. J. Dairy Sci. 73, 2386-2393

Licitra G., Hernandez T.M., Van Soest P.J., 1996. Standardization procedures for nitrogen fractionation of ruminant feeds. Anim. Feed Sci. Tech. 57, 347-358

McCleary B.V., Gibson T.S., Mugford D.C., 1997. Measurement of total starch in cereal products by amyloglucosidase - alpha-amylase method: Collaborate study. J. AOAC Int. 80, 571-579

NRC, 1996. Nutrient Requirements of Beef Cattle. 7th revised Edition. National Academy Press. Washington, DC

NRC, 2001. Nutrient Requirements of Dairy Cattle. 7th revised Edition. National Academy Press. Washington, DC

Roe M.B., Sniffen C.J., Chase L.E., 1990. Technique for measuring protein fractions in feedstuffs. Proceedings of Conell Nutrition Conference. Ithaca, NY, p. 81

Steel R.G., Torrie J.H., 1980. Principles and Procedures of Statistics. McGraw-Hill, New York

Van Soest P.J., Robertson J.B., Lewis B.A., 1991. Methods for dietary fiber, neutral detergent fiber, and non-starch polysaccharides in relation to animal nutrition. J. Dairy Sci. 74, 3583-3597

Yu P., Meier J.A., Christensen D.A., Rossnagel B.G., McKinnon J.J., 2003. Using the NRC-2001 model and the DVB/OEB system to evaluate nutritive values of Harrington (malting-type) and Valier (feed type) barley for ruminants. Anim. Feed Sci. Tech. 107, 45-60 